\author{
Military Technical College \\ Kobry Elkobbah, Cairo, \\ Egypt.
}

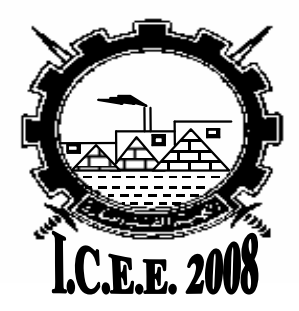

$4^{\text {th }}$ International Conference On Chemical \& Environmental Engineering 27-29 May 2008

\title{
Effect of Target And Background Temperatures on Thermal Obscuring Potentials of Some Mineral Dusts
}

\author{
H. Ramzy ${ }^{*}$, M. Sh. Fayed*, M. K. Abd El Magid*, \\ T. Melliegy* and K. Ali*
}

\begin{abstract}
A promising approach to the developments of passive countermeasures against imaging infrared seekers is airborne obscurants. The effect of target and background temperatures on the thermal obscuring potentials of different mineral dusts as airborne obscurants was studied. The target temperatures and background temperatures were within the following ranges $\left(50-200^{\circ} \mathrm{C}\right)$ and $\left(18-35^{\circ} \mathrm{C}\right)$ respectively. The airborne smoke powder was generated pneumatically within a designed smoke tunnel equipped with means for measuring the surrounding ambient temperature. The thermal obscuring potential of the smoke was tested by using a thermal camera attached to a video recorder and a data processing system. The effect of smoke on the attenuation of infrared radiation emitted from a the target was recorded, analyzed and explained.
\end{abstract}

\section{KEY WORDS}

Infrared countermeasures, powder, screening, smoke, obscurants 


\section{INTRODUCTION}

By common sense, what can be seen can be hit and killed on the battlefield. The Army uses smoke and obscurants to attack threat reconnaissance, surveillance, and target acquisition efforts. Smoke is also used to protect the forces and to support tactical deception operations. By combining obscuration with maneuver the forces could be protected and deny the threat ability to acquire and engage it [1]. Means of smoke generation developed just prior to WWII ,which made it feasible to use screen smokes extensively in both offensive and defensive operations. Screening smokes were used to conceal all types of troops movements and intallations in both combat zones and rear areas [2].

All sensory equipments require a certain amount of energy before they can perform their functions. A sensor will also fail to function if the level of energy, in the wavelength range that sensor is designed to work within, is too great [3]. The ability to detect and identify a target concealed by smoke cloud is a function of target to background contrast. Smoke cloud reduces the target to background contrast, making the target more difficult to be detected [4]. Recent developments in optoelectronics have led to more effective military systems designed for the detection of hostile targets $[5,6]$.

Generation of smoke by dispersal of powders is based on production of obscuring dust clouds by the gaseous suspension of particulate material originating from the disruption of bulk solids (blasting), or from the dispersion of finely divided powders (pneumatically). Dispersal of smoke powders pneumatically could be carried out by means of positive or negative pressure systems [7-10].

Airborne obscurants could be considered as common name for most mechanical smoke systems, which concerned with aerosolize solid particles with minor dimensions below one micron. Obscurant particles are, by necessity, high-aspect ratio, electrically conductive fibers or flakes with small minor dimensions (nanoparticles are interesting candidates) [11-13]. Traditional dissemination mechanisms are explosives, and pneumatics [14]. The thermal obscuring powders could be packed in a camouflage system such as a canister, missile, rocket or a gas generator and dispersed in the atmosphere $[15,16]$. The aim of this work is to investigate the effect of target and background temperatures on thermal obscuring potentials of some mineral dusts.

\section{EXPERIMENTAL WORK}

\subsection{Chemicals}

All the chemicals used in this experimental work were of the commercial grade. They were used directly without any purification or treatment. These chemicals are shown in table (2.1). The choice of the investigated powders was based on recent study of obscurant materials [17], the toxic hazards, explosion hazards and availability and economic aspects [18-21]. Calcium carbonate and talc powders are inflammable and do not form explosive mixture with air but ultrafine carbon black may be ignited or explode in air at temperature above $250^{\circ} \mathrm{C}$ [22-24]. 


\subsection{Instruments and Experimental Setup}

The used instruments during different steps of the experimental work are illustrated in table (2.2). Complete specification, effective working ranges, and available diagrams of the used instruments are illustrated during the description of each step of the experimental work.

Characteristics of the produced cloud of smoke were measured by thermal imager model $760 \mathrm{LW}$ Inframetrics of spectral range from $8-12 \mu \mathrm{m}$. It was equipped with TV\&videocassette recorder model Panasonic TC4SV10S to record the thermal image of the infrared black body radiator model Graseby201/546. Data processeing and analysis wrer carried out with IBM computer model 300PL pintum III series, high performance $1.2 \mathrm{GH}$ processor. The relative humidity values were measured by digital thermo-hygrometer model TFA 4001. Weighing was performed using digital analytical balance type Stanton digital balance model 351BR. Drying was carried out by drying oven of type Veb-mlw model WS3.

Experimental setup consists mainly of special designed smoke tunnel, thermal imager, data acquisition system and infrared black body [25]. its basic specifications are given in table (2.3). It is equipped with suction and recycling fans as well as measuring apparatuses to record humidity and temperature. The smoke was generated pneumatically in the tunnel by dispersion of the powder sample within sample holder which made of PVC. Figure (2.1) shows dimensional disassembly and assembly drawing of the sample holder. The maximum mass could be loaded in this holder was about $100 \mathrm{~g}$. Infrared black body radiator was used to represent a field target. Thermal imager and the accompanied devices for recording and processing were placed at the other end of the tunnel. An air curtain is applied in front of them to prevent the smoke from diffusion in the space of laboratory. The effect of smoke in reducing temperature and radiation level of the infrared black body radiator with time was recorded, graphed and analyzed for each smoke sample. The setup used for measurements is illustrated in figure. (2.1).

\subsection{Experimental studing of obscuring potentials of smoke powders.}

The smoke was generated in the smoke tunnel by pneumatic mechanism, where the outlet air from the tunnel blower disperses the smoke powder in the sample holder pushing it into the smoke tunnel in the front of the infrared black body radiator and so the smoke cloud is propagated in the tunnel. Thermal characterization of the smoke cloud was investigated by measuring the attenuation of the infrared radiation through the smoke cloud at different target and background temperatures.

\subsubsection{Preparation of Smoke Powder Samples}

The smoke samples before testing were dried and particle size was analyzed with sieves. The smoke samples were weighed with the following masses, $15.00 \mathrm{~g}$, $25.00 \mathrm{~g}, 50.00 \mathrm{~g}, 75.00 \mathrm{~g}$, and $100.00 \mathrm{~g}$. Five samples were prepared, since each experiment was repeated five times. Except carbon black samples are weighed with the following masses, $1.50 \mathrm{~g}, 2.50 \mathrm{~g}, 5.00 \mathrm{~g}, 10.00 \mathrm{~g}, 15.00 \mathrm{~g}$, and $25.00 \mathrm{~g}$.

\subsubsection{Testing of Smoke Powder Samples}

(1) The sample under testing was placed in the sample holder .

(2) The smoke tunnel circulation system and the videocassette recorder are turned on at the same time. The outlet air from the tunnel blower disperses the smoke powder sample in the sample holder pushing it into the smoke tunnel in the front of the infrared black body radiator and so the smoke cloud propagated in the tunnel. 
(3) The change in the observed temperature of the infrared black body radiator during the propagation of the smoke cloud in the tunnel and the disappearance of target thermal image is recorded on the video tape.

(4) The setup is turned off when the observed temperature of the infrared camera reaches its initial value before testing.

(5) The smoke tunnel circulation system is turned on again for $10 \mathrm{~min}$ to remove any residual powders in the tunnel from the previous experiment, and then turned off for $10 \mathrm{~min}$. This step is repeated three times to insure no residuals after each experiment.

(6) Every sample is tested five times to insure consistency and to minimize the experimental error.

(7) After testing the sample, the smoke tunnel circulation system is turned on for $30 \mathrm{~min}$ then turned off for $15 \mathrm{~min}$. This step is also repeated three times; assure that the infrared camera observes no change in the initial temperature of the target when circulation system is turned on with empty tunnel.

2.3.3 Data AnalysisExperimental data was gathered by playing the videotape in a slow motion. The variation in the temperature of infrared radiator caused by the smoke sample was tabulated with respect to time. The attenuation of infrared radiation in the range of 8-14 micrometer was calculated and represented as variation of the thermal contrast of the target at certain apparent temperature, superimposed on a certain back ground temperature [25].

\section{RESULTS AND DISCUSSION}

The effect of different mass loaded of calcium carbonate, talc powder, and carbon black on the attenuation of infrared radiation emitted from infrared black body radiator at $100^{\circ} \mathrm{C}$ and $18^{\circ} \mathrm{C}$ ambient temperature is shown in figures (3.1), (3.2), and (3.3). Table (3.1) represents a review of the obtained results. The experiments were repeated under different target temperatures and background temperatures within the following ranges $\left(50-200^{\circ} \mathrm{C}\right)$ and $\left(18-35^{\circ} \mathrm{C}\right)$ respectively.

Figure (3.1) shows the effect of calcium carbonate smoke clouds produced by different masses dispersed in the smoke tunnel on the thermal contrast. The maximum attenuation of thermal contrast augments from $47 \%$ to $80 \%$ with a corresponding increase in the duration of this maximum attenuation from 0.8 to $2 \mathrm{~S}$. respectively. By subjecting the target to talc powder as smoke producing agent with different masses, a group of curves of similar trend is shown in figure (3.2). The thermal attenuation augments from $43 \%$ to $63 \%$ with a corresponding increase in the duration of this maximum attenuation from 1.8 to $3 S$. respectively. By investigating the thermal obscuring potential of carbon black, higher extent of attenuation was achieved as shown in figure (3.3). As increasing the tested masses from one to $25 \mathrm{~g}$, the maximum thermal attenuation increased from 26 to $100 \%$ with corresponding increase in duration of these maximums attenuation from 3.1 to $7.7 \mathrm{~S}$.

Figure (3.4) shows the effect of different smoke concentrations of calcium carbonate, talc powder, and carbon black on the thermal contrast of the infrared radiation of a black body radiator at $100{ }^{\circ} \mathrm{C}$ and the ambient temperature was $18^{\circ} \mathrm{C}$. It was found that calcium carbonate achieving minimum thermal contrast lower than talc powder. The minimum contrast achieved by calcium carbonate, talc, and carbon black were 
$0.1,0.18$, and zero respectively. Only $1.23 \mathrm{~g} / \mathrm{m}^{3}$ of carbon black is sufficient to achieve $100 \%$ thermal transmittance attenuation.

\subsection{Effect of Background Temperature on Obscuring Potential}

The effect of background temperature on the thermal screening properties was tested to investigate the screening efficiency in the infrared region. The initial thermal contrast between the target at $100^{\circ} \mathrm{C}$ and the background was $0.49,0.44$, and 0.38 corresponding to background temperatures 18,25 , and $35^{\circ} \mathrm{C}$ [25]. It is clear that increasing the smoke concentration, the thermal contrast between the target and the background decreases. The obtained curves show how the thermal attenuation of the examined obscuring powders could be modified with the background temperature. The selected range of temperature could represent the normal ambient temperatures during winter and summer. The graphical relation between thermal contrast of the target and background and mass concentrations of tested powders are shown in figures (3.5), and (3.6). The obtained results are summarized in table (3.2). It was concluded that the increase in background temperature affects positively on the thermal screening efficiency of the investigated powders.

Figure (3.5) shows the effect of background temperature on the attenuation of infrared radiation by calcium carbonate. The minimums thermal contrast achieved were $0.1,0.05$, and zero at background temperatures $18^{\circ} \mathrm{C}, 25^{\circ} \mathrm{C}$, and $35^{\circ} \mathrm{C}$ respectively. The minimum smoke concentration sufficient for maximum thermal contrast attenuation was $11.3 \mathrm{~g} / \mathrm{m}^{3}$ at all background temperatures. It is clear that the thermal obscuring potential of calcium carbonate smoke increased as the background temperature increased, and so it could represent successful performance of thermal screening at $35^{\circ} \mathrm{C}$ or higher as in summer day. By subjecting the target to talc powder as smoke producing agent at different background temperatures, a group of curves of similar trend is shown in figure (3.6). The constructed curves are dependent on background temperatures. The same principle discussed before with calcium carbonate has been applied successfully, but to a lower extent of thermal contrast attenuation using the same concentrations. The minimums thermal contrast achieved were $0.18,0.13$, and 0.07 at background temperatures $18^{\circ} \mathrm{C}, 25^{\circ} \mathrm{C}$, and $35^{\circ} \mathrm{C}$ respectively. The minimum smoke concentration sufficient for maximum thermal contrast attenuation was $11.3 \mathrm{~g} / \mathrm{m}^{3}$ at all background temperatures. Figure (3.7) shows the effect of background temperature on the attenuation of infrared radiation by carbon black smoke. The minimums thermal contrast achieved was zero at all background temperatures.

The minimum smoke concentration sufficient to achieve these minimums was 1.7 $\mathrm{g} / \mathrm{m}^{3}, 1.1 \mathrm{~g} / \mathrm{m}^{3}$ and $0.6 \mathrm{~g} / \mathrm{m}^{3}$ respectively. It is clear that high background temperature improves the effectiveness of the tested smoke because of the thermal contrast between the target and background decreases as the background temperature increased

\subsection{Effect of Target Temperature on Obscuring Potential}

In this part of work, the effect of target temperature on the thermal screening properties was tested to measure the screening efficiency in the infrared region. The experiments were carried out at $30^{\circ} \mathrm{C}$ ambient temperature.

The different initial thermal contrast between the target and the background were $0.15,0.42$, and 0.7 that corresponding to initial target temperatures $50^{\circ} \mathrm{C}, 100^{\circ} \mathrm{C}$ and $200^{\circ} \mathrm{C}$ [25]. The obtained results are shown in figures (3.8), (3.9) and (3.10) and summarized in table (3.3). The photon flux emitted from a cretin target depends on its 
temperature. Increasing temperature leads to increasing the photon flux emitted from the target [26]. Increasing photon flux needs more smoke to attenuate this flux. It was found that high target temperature decreases the effectiveness of the tested smoke because of the thermal contrast between the target and background increases

Figure (3.8) shows the effect of target temperature on the efficiency of calcium carbonate smoke cloud. The maximum thermal attenuation achieved was $90 \%$, $95.2 \%$ and $100 \%$ with respect to target temperatures $200^{\circ} \mathrm{C}, 100^{\circ} \mathrm{C}$, and $50^{\circ} \mathrm{C}$ respectively. The minimum smoke concentration sufficient to achieve these minimums was $11.3 \mathrm{~g} / \mathrm{m}^{3}$ at all target temperatures. Figure (3.9) shows the effect of target temperature on the efficiency of talc smoke cloud. The maximum thermal attenuation achieved was $58.8 \%, 81.7 \%$ and $86.7 \%$ with respect to target temperatures $200^{\circ} \mathrm{C}, 100^{\circ} \mathrm{C}$, and $50^{\circ} \mathrm{C}$ respectively. The minimum smoke concentration sufficient to achieve these minimums was $11.3 \mathrm{~g} / \mathrm{m}^{3}$ at all target temperatures. Figure (3.10) shows the effect of target temperature on the efficiency of carbon black smoke cloud. The maximum thermal attenuation achieved was $100 \%$ with respect to target temperatures $200^{\circ} \mathrm{C}, 100^{\circ} \mathrm{C}$, and $50^{\circ} \mathrm{C}$ respectively. The minimum smoke concentration sufficient to achieve these minimums was $1.7 \mathrm{~g} / \mathrm{m}^{3}$, $1.25 \mathrm{~g} / \mathrm{m}^{3}$ and $0.56 \mathrm{~g} / \mathrm{m}^{3}$ respectively.

Table (3.3) indicates the effect of target temperatures on the attenuation of infrared radiation emitted from infrared black body radiator at different temperatures by calcium carbonate, talc powder, and carbon black, at $30^{\circ} \mathrm{C}$ ambient temperature. The smoke concentration sufficient for $80 \%$ and $90 \%$ thermal attenuation increases as the target temperature increases. The maximum thermal contrast attenuation increases as the target temperature decreases. It was concluded that carbon black achieves the higher thermal contrast attenuation for all target temperature. Calcium carbonate achieves $100 \%$ thermal contrast attenuation for target temperature $50^{\circ} \mathrm{C}$

\section{CONCLUSIONS}

The experimental results and theoretical discussions indicate the capability of experimentally studying the potential of various powders as infrared obscurants and investigate their obscuring potentials under the effect of different target and background temperatures

The main conclusions of the present work are:

[1] The increase in background temperature affects positively on the infrared obscuring potential of the smoke cloud, and the increase in target temperature affects negatively on the infrared obscuring potential of the smoke cloud

[2] Carbon black shows the best obscuring potentials for all target and background temperatures, even at high target temperatures and cold background temperatures.

[3] Calcium carbonate could achieve acceptable obscuring potentials at relatively low target temperatures and high background temperatures.

[4] The obscuring potentials of talc enhancement at relatively low target temperatures and high background temperatures, but with lower extent than calcium carbonate 


\section{REFERENCES}

[1] Headquarters Departments Of USA Army, "Smoke Operations", Field Manual 3-50, Washington, DC, 1990.

[2] ]Headquarters Departments Of USA Army, "Military Chemistry And Chemical Compounds", Field Manual 3-9, Washington, DC, 1975.

[3] Lewis J. P. "Electro Optics", John Wiley \& Sons, 1985.

[4] Ronald G. D., Paul C., And Timorthy E.,"Introduction To Infrared And ElectroOptical Systems", Artech House Press,1999.

[5] Hudson R. D.; "Infrared System Engineering “ ; 1st Edition , John Wiley Press, 1975

[6] Chrzanowski K. "Radiometry In Military Applications" Proceeding Of SPIE International Society Of Optical Engineering V4517, P 1-15, 2001.

[7] Piepenborck P. G., "Powder For Producing Smoke Screen Contains Dolomite With Addition Of Silicon, Aluminum, Iron, Potassium And Sodium To Provide High Cover Time", Patent Number: DE 3918231, 1990.

[8] Wulvik E., "Arrangement In Smoke Camouflage System", Patent Number: US 5233927, 1993.

[9] Sellmen L. R, Embury J. R. And Beyth W. W., "Method Of Forming IR Smoke Screen", Patent Number: US 4704966, 1987.

[10] Larmignat D., Morand P., Prieur C. And Lacreuse G., "Material For Efficient Masking In The Infrared Region ", Patent Number: US 5340395, 1994

[11] Susan T.P., Kristen J .M., Alan H. G.,. Terry R. L. And Mitchell R. Z., "Conductive Polymer Blends For Non Toxic Obscurant Materials", US Army Edgewood Chemical Biological Center.

[12] Janon E., "Optimum Smoke Nanoparticles That Maximize Attenuation At Infrared And Radar Wavelengths", Edgewood Chemical Biological Center, 2002.

[13] United Stats Department Of Defense "Developing Critical Technologies/Science \& Technology (DCT/S\&T): Section 5: Chemical Technology", Defense Threat Reduction Agency, 2000.

[14] The United States Army Research Office (ARO), "Obscurant Dissemination", ARMY03-T21, Army Research Laboratory (ARL), STTR Program, 2003.

[15] Block K. A.; Carter W. M.; And Schillreff G. H. "Decoy Rounds And Their Method Of Fabrication", Patent Number: US4286498, 1981.

[16] Erickson M. L; Lowe L. R; Milstead L. R; And Schnepfe JR. Robert W., "Method Of Assembly Of Compacted Particulates And Explosive Charge", Patent Number: US4704967, 1987.

[17] H. Ramzy, M. Sh. Fayed, M. K. Abd El Magid, And T. Melliegy, "Stdying The Obscuring Potentials Of Some Mineral Dusts", $3^{\text {rd }}$ CEE Conference, Military Technical College Cairo, Egypt, May.2005

[18] Greenwood N.N And Eanshaw A., "Chemistry Of Elements", Pergmon Press, 1984.

[19] David R, "CRC Handbook Of Chemistry And Physics", CRC Press, Boca Raton, 1994.

[20] Richard J., And Lewis S. "Hazardous Chemicals Desk Reference", Fifth Edition, John Wiely Press, 2003

[21] George W. "Handbook Of Fillers", 2nd Edition, Chem. Tec. Publishing, 2000.

[22] Bretherick L.; "Handbook Of Reactive Chemical Hazards", Fourth Edition, Butterwarths Press, 1990. 
[23] Hugh O. P.; "Handbook Of Carbon, Graphite, Diamond, And Fullerences" Noyes Publications, 1993

[24] Annual Book Of ASTM Standards, "Standard Tests Method For Ignition Temperature Of Active Carbon", D3466, 1993

[25] Ramzy H.,"Generation And Characterization Of Some Aerosols Aginst Infrared Sensors", MSC. , MTC, Cairo,2005

[26] Harrison "Electro-Optic Handbook", RCA Press, 1974. 
Table (2.1) Chemicals used in the present work and their toxicity limits [18-22].

\begin{tabular}{|l|c|c|c|}
\hline \multicolumn{1}{|c|}{ Smoke producing powder } & $\begin{array}{c}\text { Calcium } \\
\text { carbonate }\end{array}$ & $\begin{array}{c}\text { Talc powder } \\
\text { (Magnesium } \\
\text { silicates) }\end{array}$ & Carbon black \\
\hline Chemical formula & $\mathrm{CaCO}_{3}$ & $\mathrm{Mg}_{3} \mathrm{Si}_{4} \mathrm{O}_{10}(\mathrm{OH})_{2}$ & $\mathrm{C}$ \\
\hline $\mathrm{M}_{\cdot \text { wt }}(\mathrm{g} / \mathrm{mol})$ & 100.09 & 379.29 & 12.011 \\
\hline Particle size range $(\mu \mathrm{m})$ & $0.2-30$ & $10-40$ & $1.4-25$ \\
\hline Density $\left(\mathrm{g} / \mathrm{cm}^{3}\right)$ & 2.93 & $2.7-2.8$ & $1.8-2.1$ \\
\hline $\mathrm{TLV}\left(\mathrm{mg} / \mathrm{m}^{3}\right)$ & 15 & 2.5 & 3.5 \\
\hline Supplier & $\begin{array}{c}\text { MENA } \\
\text { company } \\
\text { (Egypt) }\end{array}$ & $\begin{array}{c}\text { EJICM company } \\
\text { (Egypt) }\end{array}$ & $\begin{array}{c}\text { Columbian } \\
\text { chemical } \\
\text { company (USA) }\end{array}$ \\
\hline
\end{tabular}

Table (2.2) Instruments used in the present experimental work.

\begin{tabular}{|c|c|c|c|}
\hline No & Instruments & Model & Using \\
\hline 1 & Thermal imager & Inframetrics 760 LW & Experimental setup \\
\hline 2 & TV videocassette recorder & $\begin{array}{c}\text { PanasonicTC- } \\
\text { 14SV10S }\end{array}$ & Experimental setup \\
\hline 3 & Infrared black body radiator & Graseby201/546 & Experimental setup \\
\hline 4 & Sample holder & Local fabrication & Experimental setup \\
\hline 5 & Smoke tunnel & Local fabrication & Experimental setup \\
\hline 6 & Digital thermo-hygrometer & TFA 4001 & Experimental setup \\
\hline 7 & Wind velocity meter & Waren H128 & Experimental setup \\
\hline 8 & PC computer & Pintum III 300PL & Data Analysis \\
\hline 9 & Digital balance & Stanton 351BR & Sample preparation \\
\hline 10 & Drying oven & VEB-MLW WS3 & Sample preparation \\
\hline 11 & Dental vibrator( Sieving) & DV34 & Sample preparation \\
\hline 12 & Mixing unit (rotating drum) & Local & Sample preparation \\
\hline
\end{tabular}

Table (2.3) Basic specification of the used smoke tunnel [25].

\begin{tabular}{||c|c||}
\hline Item & Specification \\
\hline Material & iron sheets \\
\hline Cross-section & $0.8 \times 0.8 \mathrm{~m}$ \\
\hline Length & $6 \mathrm{~m}$ \\
\hline $\begin{array}{c}\text { Average air } \\
\text { velocity }\end{array}$ & $0.4 \mathrm{~m} / \mathrm{s}$ \\
\hline Total volume & $8.85 \mathrm{~m}^{3}$ \\
\hline Blower power & $2 \mathrm{hp}$ \\
\hline
\end{tabular}


Table (3.1) the effect of different mass loaded of calcium carbonate, talc powder, and carbon black on the attenuation of infrared radiation emitted from infrared black body radiator at $100^{\circ} \mathrm{C}$ and $18^{\circ} \mathrm{C}$ ambient temperature.

\begin{tabular}{|c|c|c|c|c|c|c|c|c|c|c|c|c|c|c|c|c|}
\hline Smoke powder & \multicolumn{5}{|c|}{ Calcium carbonate } & \multicolumn{5}{|c|}{ Talc powder } & \multicolumn{6}{|c|}{ Carbon black } \\
\hline $\begin{array}{l}\text { Mass loaded in the } \\
\text { smoke tunnel }(\mathrm{g})\end{array}$ & 15 & 25 & 50 & 75 & 100 & 15 & 25 & 50 & 75 & 100 & 1 & 2.5 & 5 & 10 & 15 & 25 \\
\hline $\begin{array}{c}\text { Time sufficient for } 80 \% \\
\text { attenuation (S..) }\end{array}$ & --- & ---- & -- & 9 & 8 & -- & -- & -- & -- & -- & -- & -- & 7 & 3.5 & 2.5 & 1.2 \\
\hline $\begin{array}{l}\text { Time duration for } 80 \% \\
\text { attenuation (S..) }\end{array}$ & --- & ---- & -- & 4 & 11.3 & -- & -- & -- & -- & -- & -- & -- & 20 & 37.5 & 44.5 & 53.8 \\
\hline $\begin{array}{l}\text { Time sufficient for } 90 \% \\
\text { attenuation (S..) }\end{array}$ & --- & ---- & -- & -- & -- & -- & -- & -- & - & -- & -- & -- & 11.5 & 5.5 & 4.3 & 3 \\
\hline $\begin{array}{l}\text { Time duration for } 90 \% \\
\text { attenuation (S..) }\end{array}$ & $\begin{array}{c}--- \\
-\end{array}$ & - & -- & -- & --- & -- & -- & -- & -- & -- & -- & -- & 5 & 25.5 & 30.5 & 52 \\
\hline $\begin{array}{c}\text { The proposed } \\
\text { maximum mass } \\
\text { concentrations }\left(\mathrm{g} / \mathrm{m}^{3}\right)\end{array}$ & 1.7 & 2.8 & 5.6 & 8.5 & 11.3 & 1.7 & 2.8 & 5.6 & 8.5 & 11.3 & 0.11 & 0.28 & 0.56 & 1.13 & 1.7 & 2.8 \\
\hline $\begin{array}{c}\text { Maximum attenuation } \\
(\%)\end{array}$ & 48 & 57 & 67 & 73 & 80 & 43 & 50 & 59 & 61 & 63 & 39 & 53 & 82 & 98 & 100 & 100 \\
\hline $\begin{array}{l}\text { Time duration for } \\
\text { maximum attenuation } \\
\text { (S..) }\end{array}$ & 0.8 & 1 & 1.1 & 1.3 & 2 & 1.8 & 2.1 & 2.4 & 2.6 & 3 & 4 & 5.5 & 6 & 7 & 12 & 18 \\
\hline
\end{tabular}

Table (3.2) The effect of different background temperatures on the attenuation of infrared radiation emitted from black body radiator at $100^{\circ} \mathrm{C}$ by calcium carbonate and talc powder.

\begin{tabular}{|c|c|c|c|c|c|c|c|c|c|}
\hline \multirow{2}{*}{$\begin{array}{c}\text { Smoke powder } \\
\text { Background temperatures }\end{array}$} & \multicolumn{3}{|c|}{ Calcium carbonate } & \multicolumn{3}{|c|}{ Talc powder } & \multicolumn{3}{|c|}{ Carbon black } \\
\hline & $18^{\circ} \mathrm{C}$ & $25^{\circ} \mathrm{C}$ & $35^{\circ} \mathrm{C}$ & $18^{\circ} \mathrm{C}$ & $25^{\circ} \mathrm{C}$ & $35^{\circ} \mathrm{C}$ & $18^{\circ} \mathrm{C}$ & $25^{\circ} \mathrm{C}$ & $35^{\circ} \mathrm{C}$ \\
\hline $\begin{array}{l}\text { Smoke concentration sufficient for } 80 \% \text { thermal contrast } \\
\text { attenuation. }\left(\mathrm{g} / \mathrm{m}^{3}\right)\end{array}$ & 11.3 & 9 & 5.2 & --- & ---- & 6.5 & 0.39 & 0.44 & 0.53 \\
\hline $\begin{array}{l}\text { Smoke concentration sufficient for } 90 \% \text { thermal contrast } \\
\text { attenuation. }\left(\mathrm{g} / \mathrm{m}^{3}\right)\end{array}$ & --- & --- & 6.5 & ---- & --- & --- & 0.45 & 0.53 & 0.76 \\
\hline Maximum thermal contrast attenuation (\%) & 80 & 88.6 & 100 & 63 & 70 & 86.8 & 100 & 100 & 100 \\
\hline $\begin{array}{c}\text { Minimum Smoke concentration sufficient for maximum } \\
\text { thermal contrast attenuation. }\left(\mathrm{g} / \mathrm{m}^{3}\right)\end{array}$ & 11.3 & 11.3 & 11.3 & 11.3 & 11.3 & 11.3 & 1.7 & 1.1 & 0.6 \\
\hline
\end{tabular}

Table (3.3) the effect of different target temperatures on the attenuation of infrared radiation emitted from infrared black body radiator at different temperatures by calcium carbonate, talc powder, and carbon black, at $30^{\circ} \mathrm{C}$ ambient temperature.

\begin{tabular}{|c|c|c|c|c|c|c|c|c|c|}
\hline Smoke powder & \multicolumn{3}{|c|}{ Calcium carbonate } & \multicolumn{3}{|c|}{ Talc powder } & \multicolumn{3}{|c|}{ Carbon black } \\
\hline Target temperatures & $200^{\circ} \mathrm{C}$ & $100^{\circ} \mathrm{C}$ & $50^{\circ} \mathrm{C}$ & $200^{\circ} \mathrm{C}$ & $100^{\circ} \mathrm{C}$ & $50^{\circ} \mathrm{C}$ & $200^{\circ} \mathrm{C}$ & $100^{\circ} \mathrm{C}$ & $50^{\circ} \mathrm{C}$ \\
\hline $\begin{array}{l}\text { Smoke concentration sufficient for } 80 \% \text { thermal } \\
\text { contrast attenuation. }\left(\mathrm{g} / \mathrm{m}^{3}\right)\end{array}$ & 9.55 & 6.3 & 6.2 & --- & 11.2 & 6.3 & 0.62 & 0.52 & 0.38 \\
\hline $\begin{array}{l}\text { Smoke concentration sufficient for } 90 \% \text { thermal } \\
\text { contrast attenuation. }\left(\mathrm{g} / \mathrm{m}^{3}\right)\end{array}$ & 11.3 & 9.3 & 9.1 & --- & --- & --- & 0.85 & 0.8 & 0.45 \\
\hline Maximum thermal contrast attenuation (\%) & 90 & 95.2 & 100 & 58.8 & 81.7 & 86.7 & 100 & 100 & 100 \\
\hline $\begin{array}{l}\text { Minimum concentration sufficient for maximum } \\
\text { attenuation. }\left(\mathrm{g} / \mathrm{m}^{3}\right)\end{array}$ & 11.3 & 11.3 & 11.3 & 11.3 & 11.3 & 11.3 & 1.7 & 1.25 & 0.56 \\
\hline
\end{tabular}




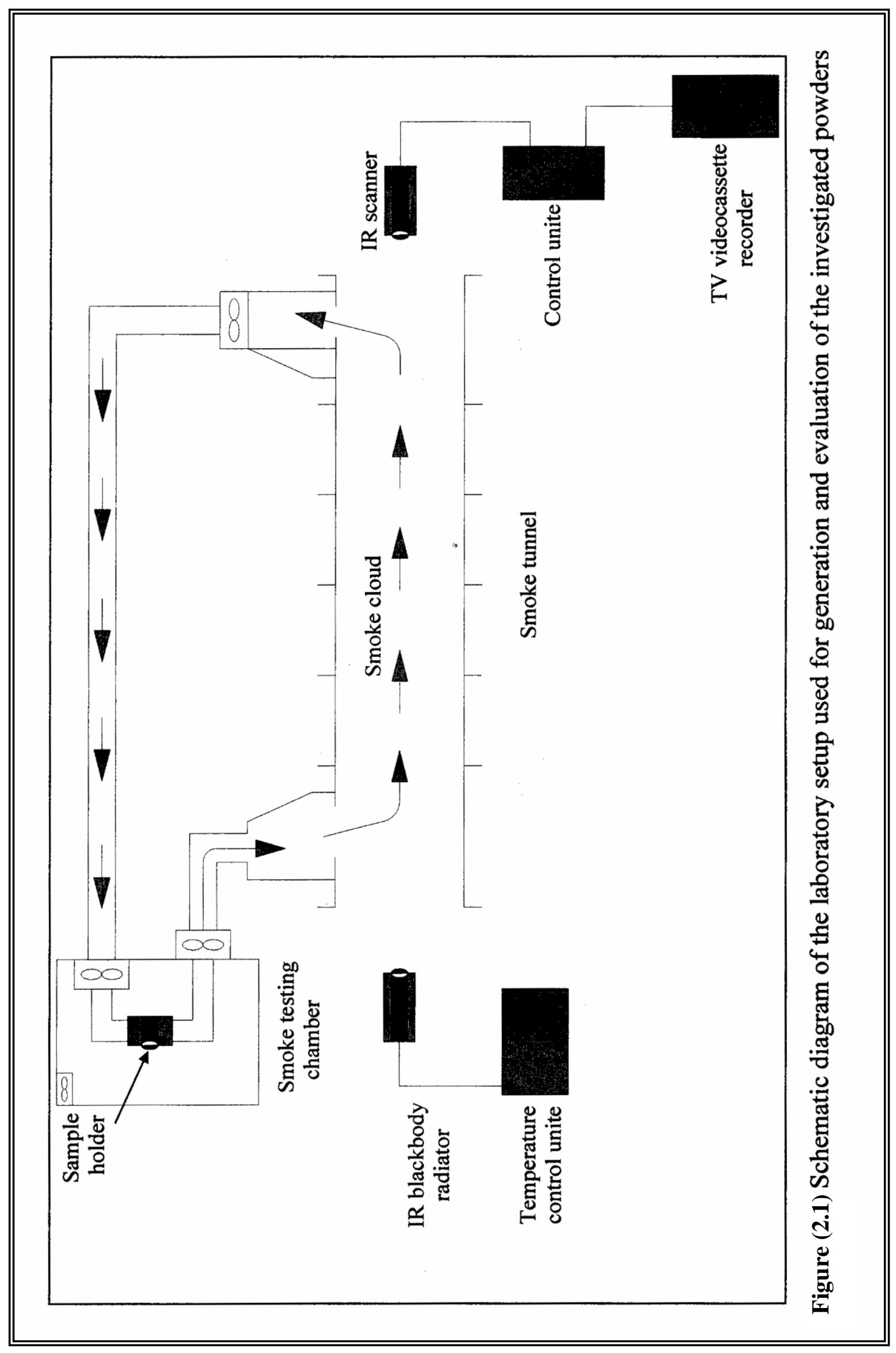




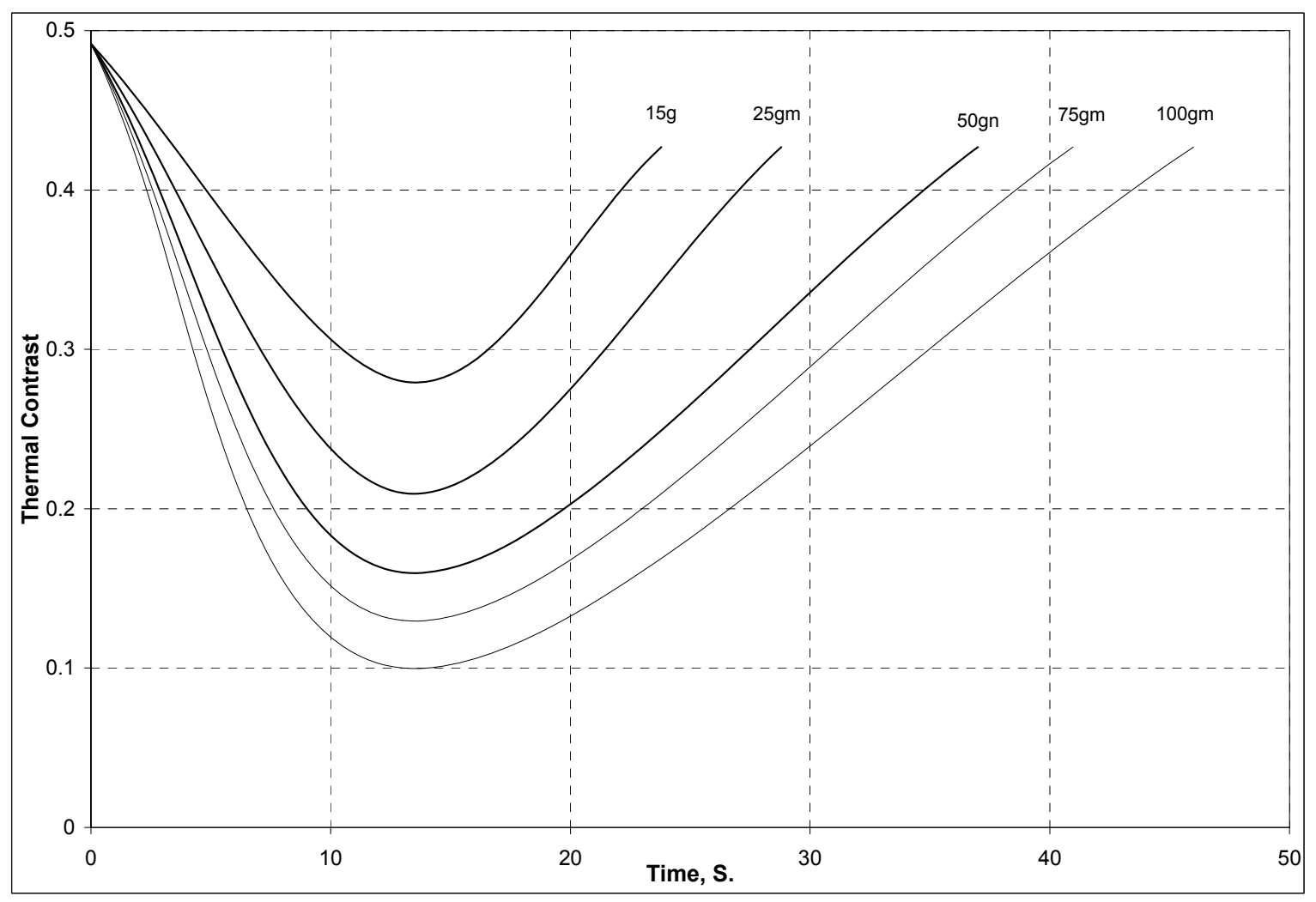

Figure (3.1) The attenuation of infrared radiation emitted from black body radiator at $100 \mathrm{oC}$ by calcium carbonate at $180 \mathrm{C}$ ambient temperature

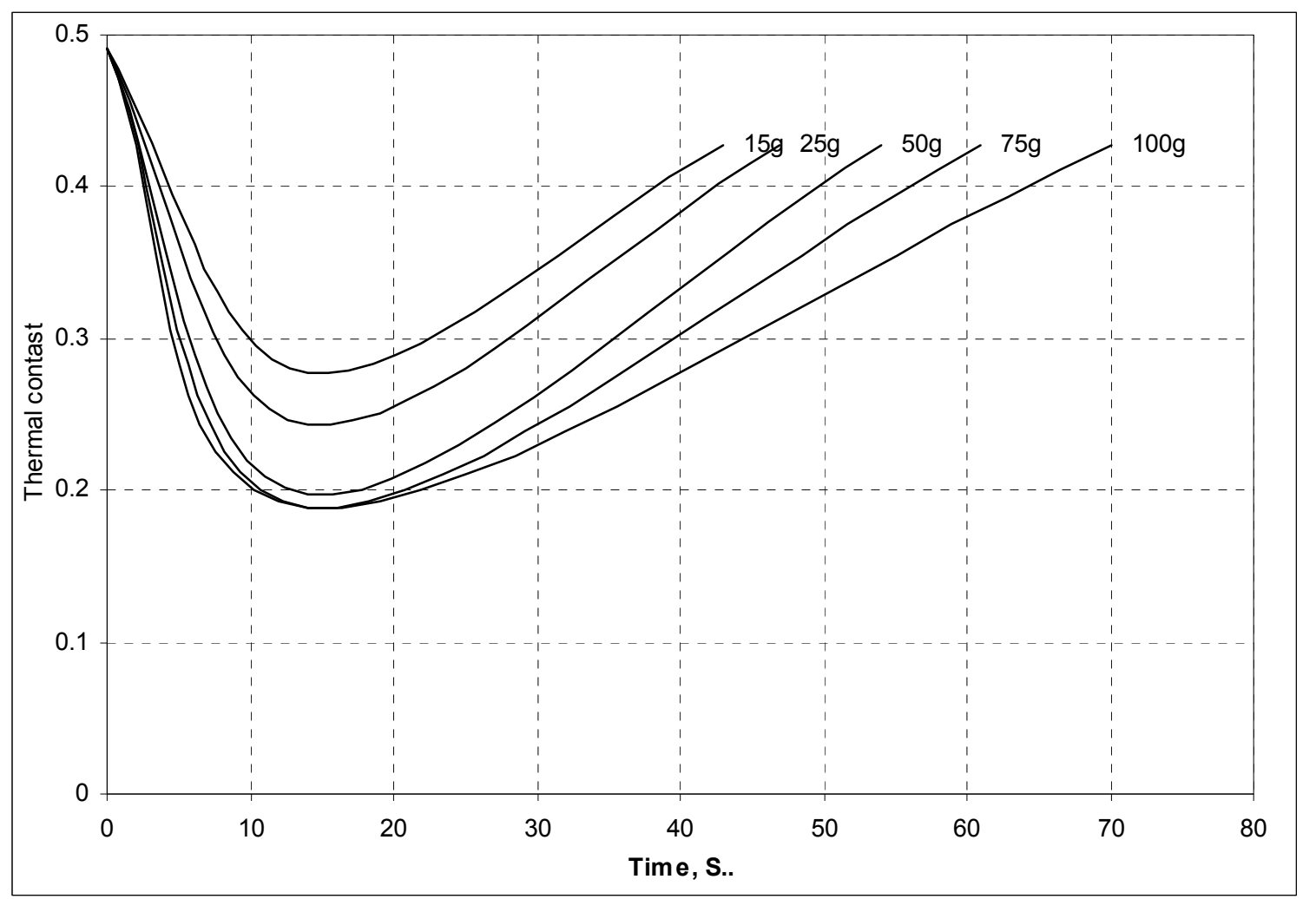

Figure (3.2) The attenuation of infrared radiation emitted from black body radiator at $1000 \mathrm{C}$ by talc powder at $180 \mathrm{C}$ ambient temperature 


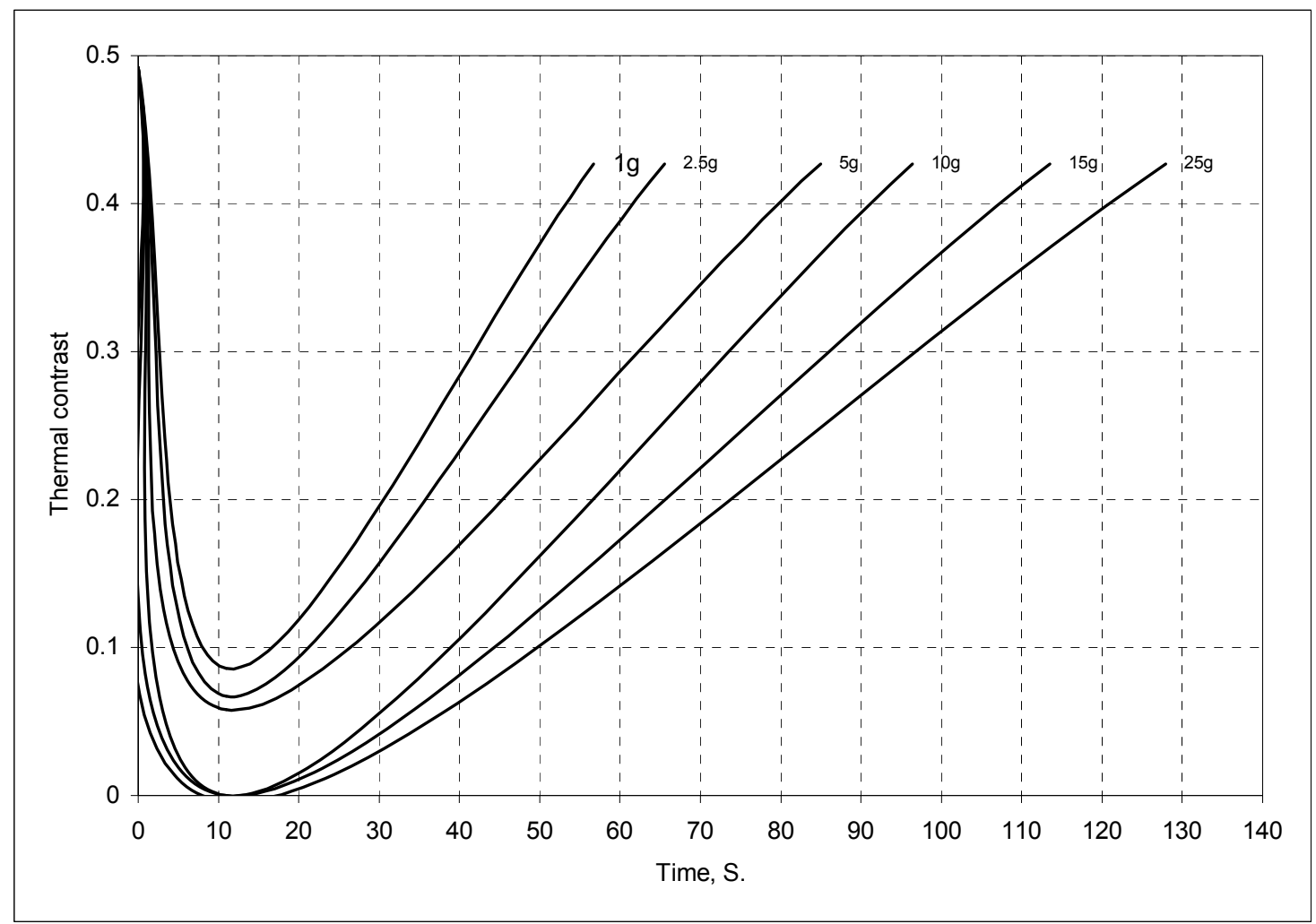

Figure (3.3) The attenuation of infrared radiation emitted from black body radiator at $100 \mathrm{oC}$ by carbon black at $180 \mathrm{C}$ ambient temperature.

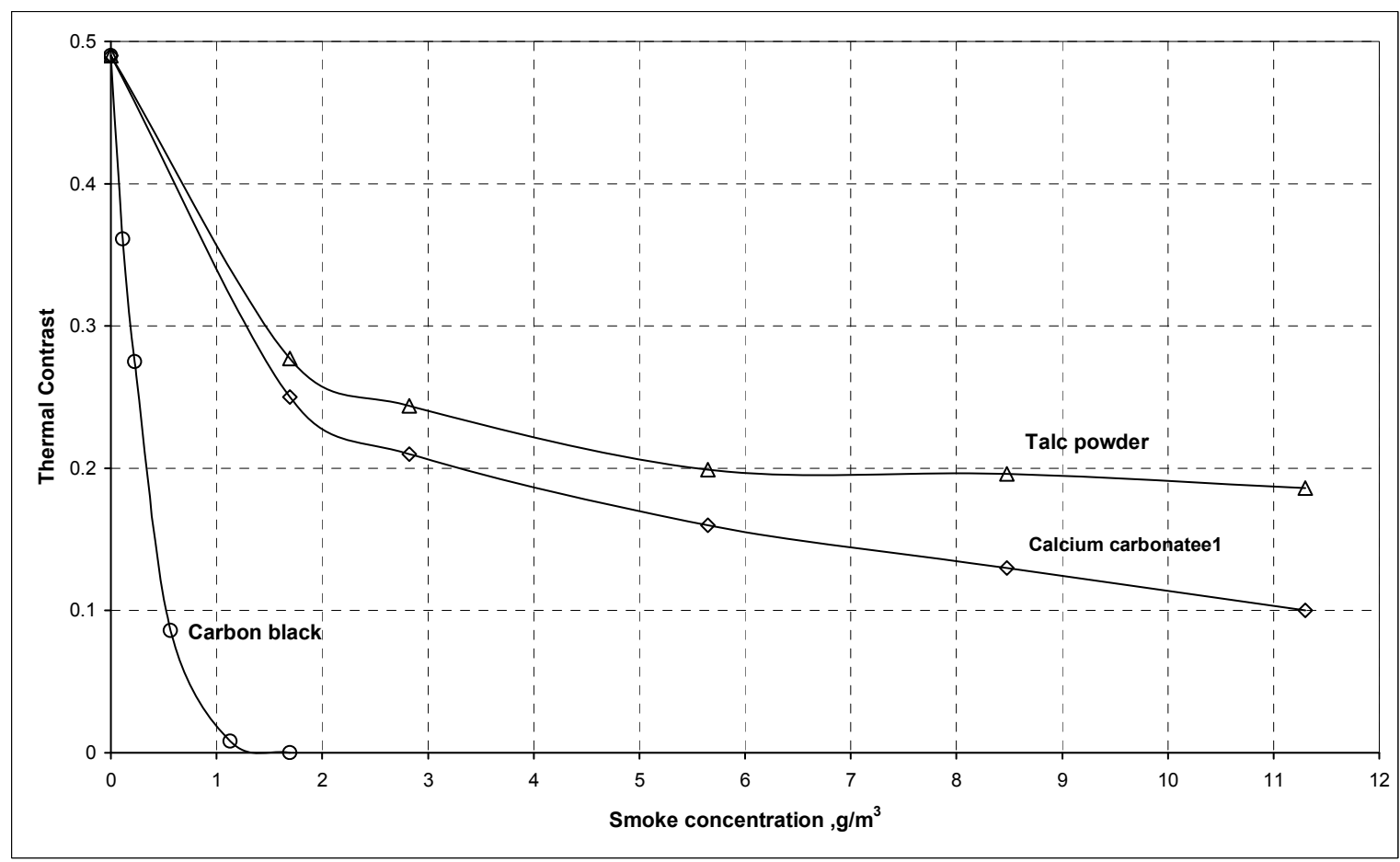

Figure (3.4) The effect of calcium carbonate, talc powder, and carbon black smoke concentrations on the thermal contrast of infrared radiation of black body at temperature $100 \mathrm{oC}$ and $180 \mathrm{C}$ ambient temperature. 


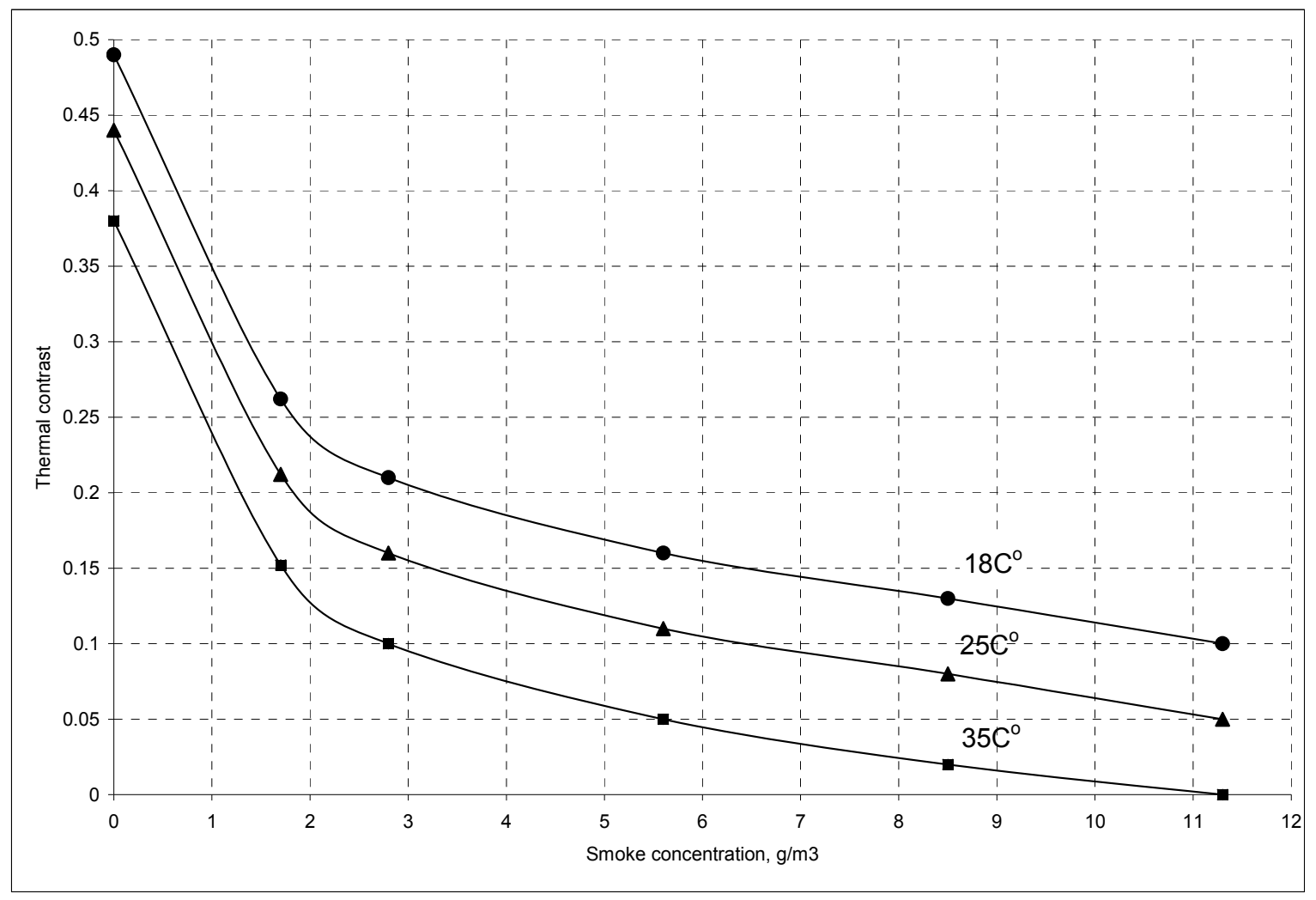

Figure (3.5) The attenuation of infrared radiation emitted from black body radiator at $100 \circ \mathrm{C}$ by calcium carbonate at different background temperatures

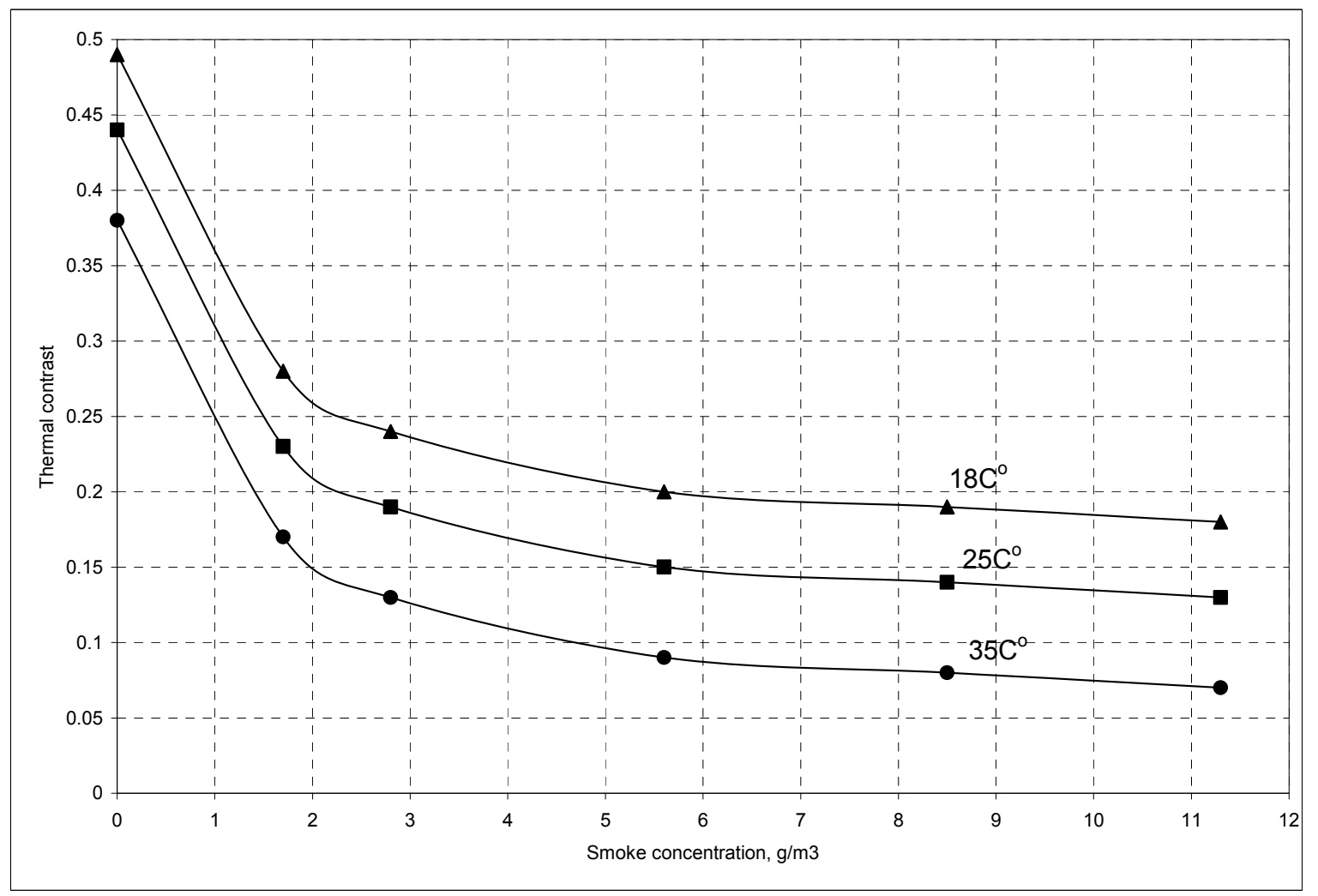

Figure (3.6) The attenuation of infrared radiation emitted from black body radiator at $100 \mathrm{oC}$ by talc powder at different background temperatures 


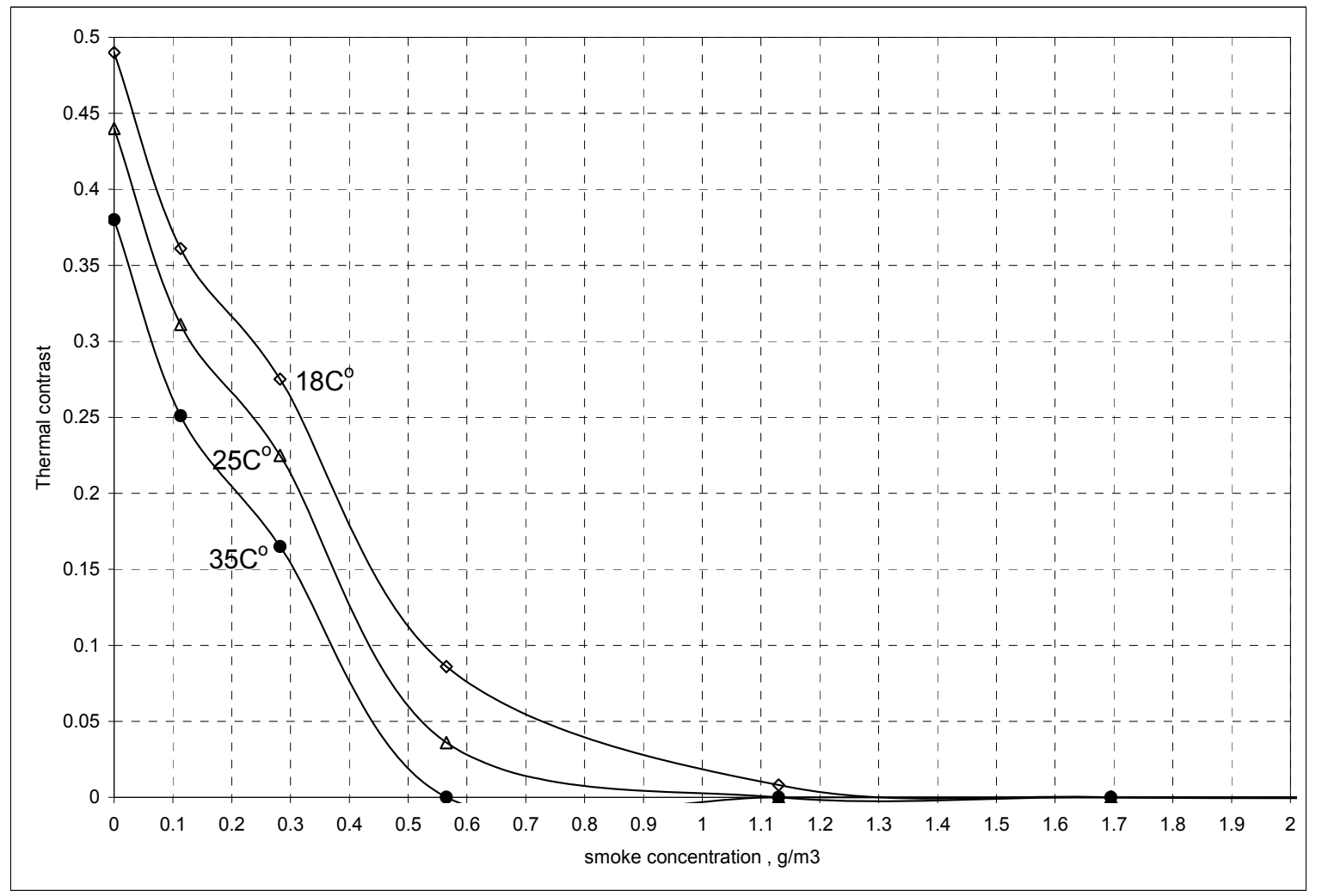

Figure (3.7) The attenuation of infrared radiation emitted from black body radiator at $1000 \mathrm{C}$ by carbon black powder at different background temperatures

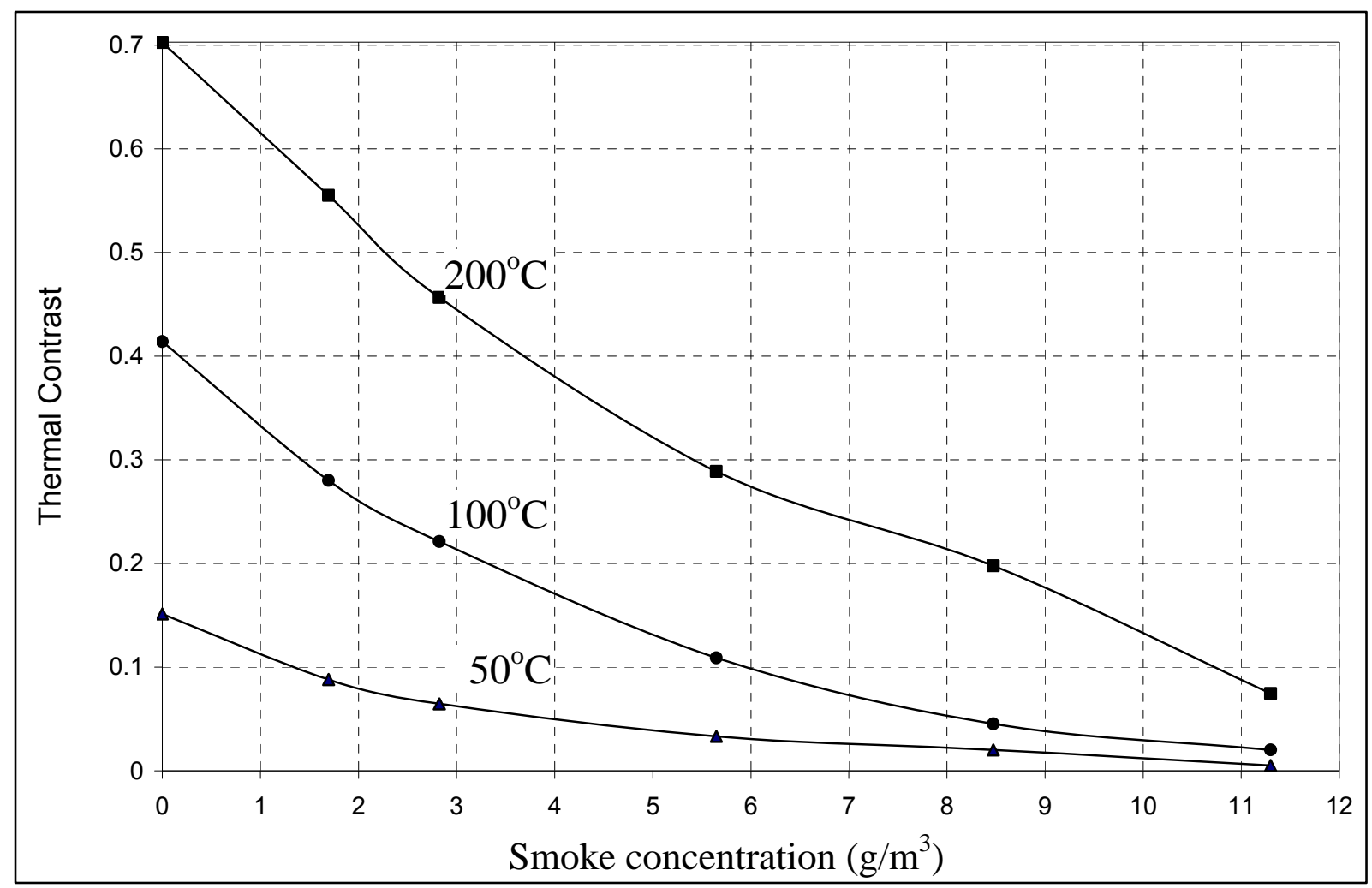

Figure (3.8) The attenuation of infrared radiation emitted from black body radiator at different temperatures by calcium carbonate. Ambient temperature $30^{\circ} \mathrm{C}$ and relative humidity $50 \%$ 


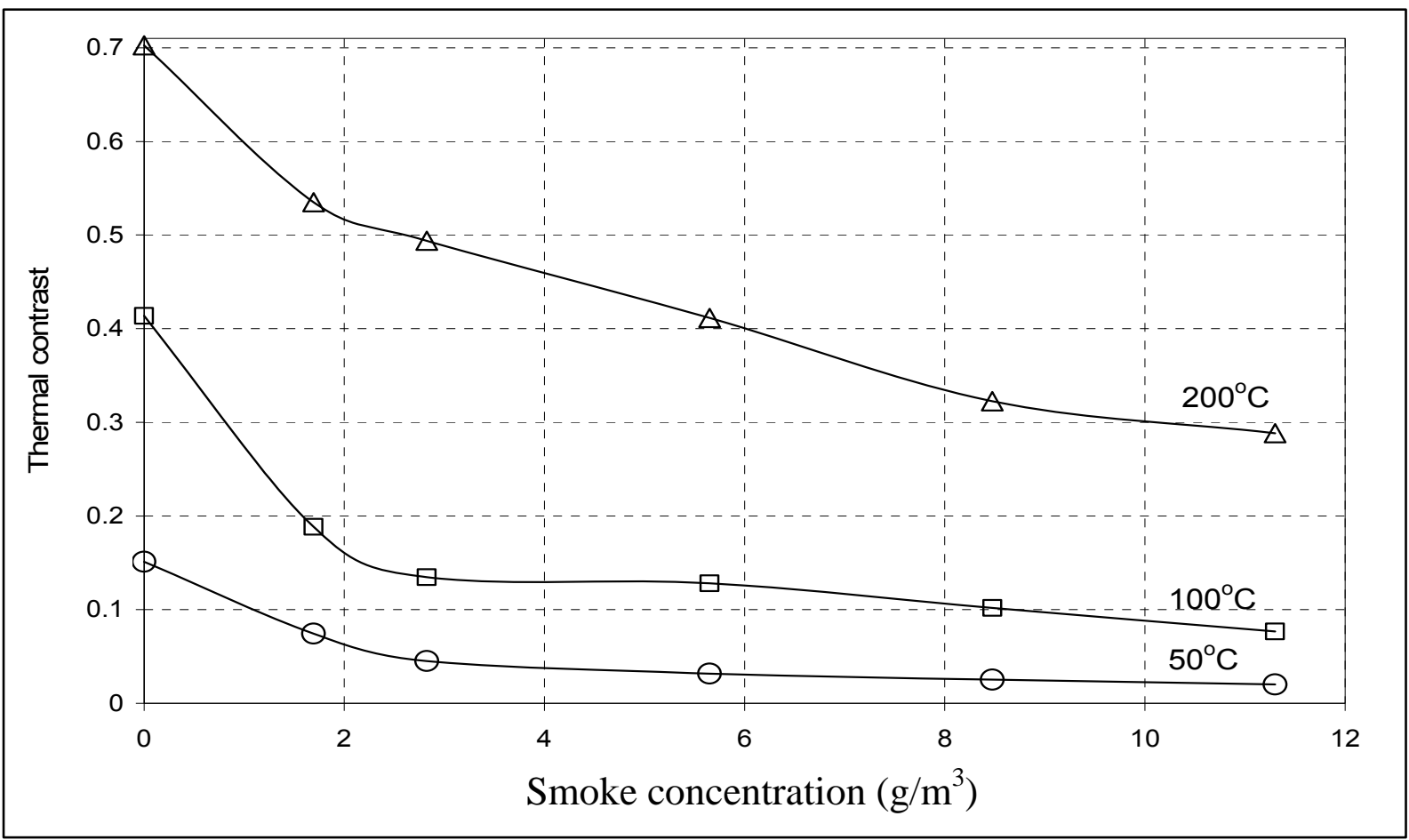

Figure (3.9) The attenuation of infrared radiation emitted from black body radiator at different temperatures by talc powder. Ambient temperature $30 \mathrm{oC}$ and relative humidity $50 \%$

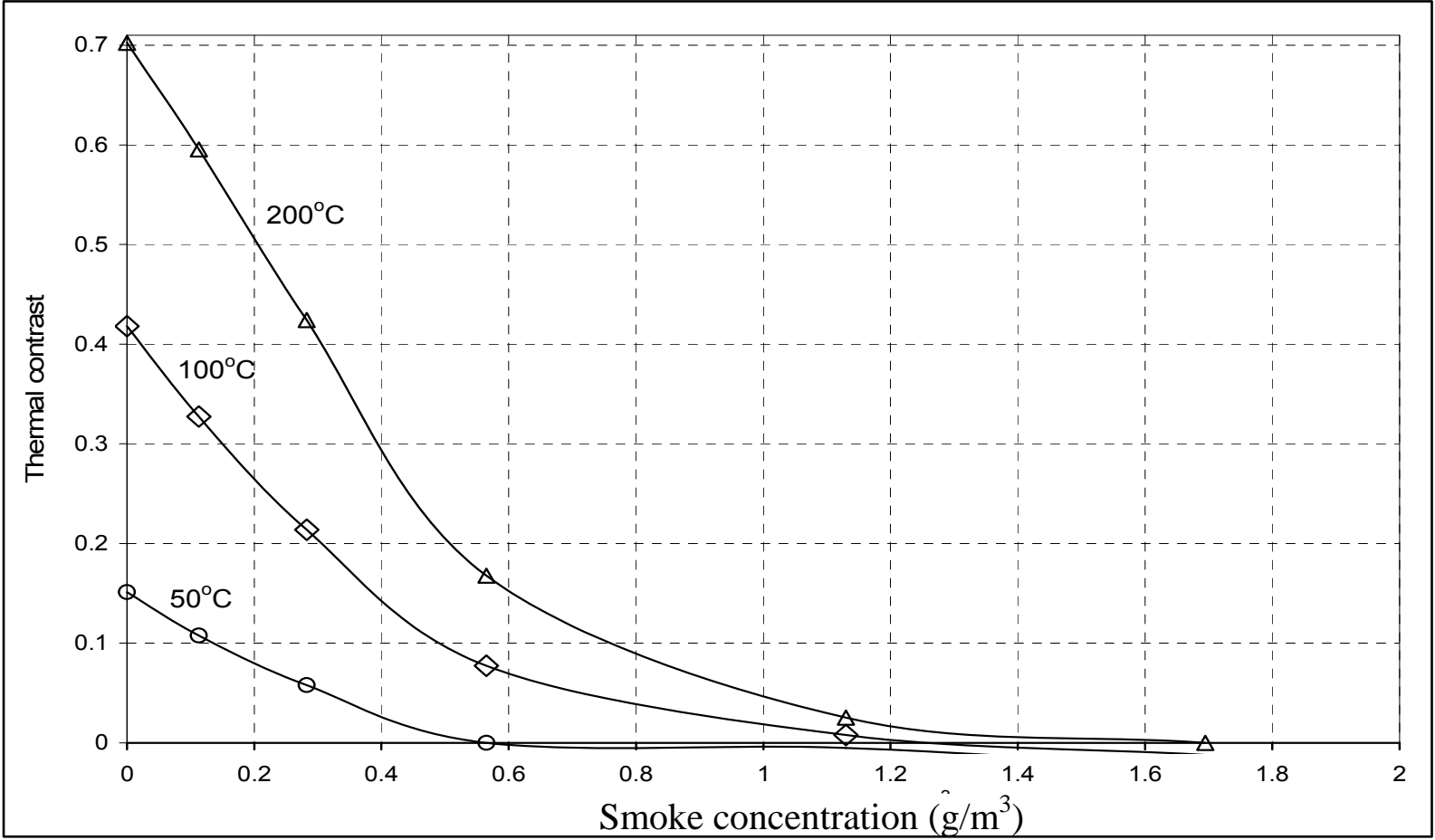

Figure (3.10) The attenuation of infrared radiation emitted from black body radiator at different temperatures by carbon black. Ambient temperature $30 \circ \mathrm{C}$ and relative humidity $50 \%$ 